JUPIIS: Jurnal Pendidikan Ilmu-ilmu Sosial, 12(2) (2020): 469-474

DOI: https://doi.org/10.24114/jupiis.v12i2.18176

JUPIIS: Jurnal Pendidikan Ilmu-ilmu Sosial

Available online http://iurnal.unimed.ac.id/2012/index.php/iupiis

\title{
Pola Okupasi Ruang Publik oleh Organisasi Kepemudaan di Kota Medan Sumatera Utara
}

\section{Occupation Patterns of Public Spaces by Youth Organizations in Medan City, North Sumatra}

\author{
Budi Saputra*, Hidayat \& Ichwan Azhari \\ Program Pasca Sarjana Antropologi Sosial, Universitas Negeri Medan, Indonesia
}

Diterima: 27 Mei 2020; Disetujui:14 September 2020; Dipublish: Desember 2020

\begin{abstract}
Abstrak
Tulisan ini bertujuan untuk mengetahui pola okupasi ruang publik dan penguasaan lahan yang dilakukan oleh Organisasi Kepemudaan di Kota Medan. Ruang publik yang dimaksud adalah lahan parkiran, keamananan pasar tradisional dan tempat hiburan, terletak di suatu lokasi yang dikuasai oleh salah satu organisasi kepemudaan, lokasi ini harus dijaga agar tidak dikuasai oleh organisasi kepemudaan lainnya. Metode penelitian yang digunakan adalah metode kualitatfi dengan pendekatan etnografi dan tekhnik pengumpulan data menggunakan observasi partisipasi dan wawancara. Hasil dari penelitian ini menjelaskan pola yang dilakukan dalam menguasai ruang publik ini dengan melakukan kerjasama (patron-client) terhadap pihak terkait seperti Perusahaan Daerah Pasar, Dinas Perhubungan dan Pemerintah Kota. Kerjasama tersebut dilakukan dengan memberikan sejumlah dana akomodasi kepada dinas tersebut dalam bentuk setoran dan tender. Mereka melakukan kerjasama juga dengan pihak swasta seperti developer property agar mendapatkan izin untuk menyediakan bahan material bangunan. Dalam melancarkan okupasi ruang publik dan penguasaan lahan, tidak sedikit dari pimpinan atau anggota Organisasi Kepemudaan masuk ke ranah politik seperti menjadi anggota DPRD, sehingga anggota tersebut memiliki kekuatan untuk menyalurkan tender atau proyek dari pemerintah maupun swasta.
\end{abstract}

Kata Kunci: Pola Okupasi, Ruang Publik dan Organisasi Kepemudaan

\begin{abstract}
This paper aims to determine the patterns of occupation of public space and land tenure carried out by the Youth Organization in the City of Medan. The intended public space is a parking lot, security of traditional markets and entertainment venues, located in a location controlled by one of the youth organizations, this location must be protected so that it is not controlled by other youth organizations. The research method used is the qualitative method with ethnographic approach and data collection techniques using participant observation and interviews. The results of this study explain the pattern carried out in controlling this public space by collaborating (patron-client) with related parties such as regional market companies, the Department of Transportation and the City Government. The collaboration was carried out by providing a number of accommodation funds to the service in the form of deposits and tenders. The cooperating with private parties such as property developers in order to get permission to provide building materials, the tender for the supply of project materials must pass the youth organization, In launching occupation of public space and land tenure. Not a few of the leaders or members of the Youth Organization entered the political sphere such as becoming a member of the DPRD, so the member had the power to distribute tenders or government projects or private.
\end{abstract}

Keyword: Occupational Patterns, Public Spaces and Youth Organizations

How to Cite: Saputra, B., Hidayat \& Azhari, I., (2020). Pola Okupasi Ruang Publik Oleh OKP di Kota Medan Sumatera Utara. JUPIIS: Jurnal Pendidikan Ilmu-ilmu Sosial, 12(2): 469-474.

\begin{tabular}{lr}
\hline$*$ Corresponding author: & ISSN 2549-1660 (Print) \\
E-mail: budisaputra@gmail.com & ISSN 2550-1305 (Online)
\end{tabular}




\section{PENDAHULUAN}

Di negara Indonesia banyak memiliki organisasi kepemudaan yang berlatar belakang adat, agama, budaya, ekonomi dan politik, namun dewasa ini Organisasi Kepemudaan (OKP) dianggap sebagai organisasi politik terkhusus di Kota Medan, karena selalu memiliki patron-client Partai Politik. OKP tumbuh subur sebagai salah satu kekuatan sosial politik masyarakat Medan yang cukup diperhitungkan. Potensi pemuda dan OKP yang sangat banyak diharapkan yaitu dapat diandalkan sebagai agen sosial, kekuatan moral dan kontrol sosial.dari beragam fakta membuktikan bahwa inovasi dan kreativitas pemuda mampu memberikan sumbangsih dalam bidang pengetahuan dan keterampilan, pemuda juga sudah membuktikan dari catatan sejarah mampu berperan sebagai kontrol sosial, baik dalam pelaksanaan pembangunan maupun roda pemerintahan dan kehidupan bernegara (Abdul, 1997; Aziz, 2013; Bonde, 2018; Fitrah, 2016).

Kebangkitan Nasional 1908, Sumpah Pemuda 1928, Proklamasi Kemerdekaan RI 1945 hingga Reformasi 1998 dimotori oleh gerakan pemuda (Ningtyas, 2019; Nirmalasari, 2018; Nurdiansyah, 2013; Susilawati, 2017; Widiatmaka. 2016). Medan salah satu kota yang tumbuh dan berkembangnya beragam OKP. OKP itu terbentuk dilandasi berdasarkan ideologi nasionalis yang berazaskan Pancasila dengan latar belakang yang berbeda-beda dan dilandasi kesadaran demokrasi maupun yang tidak, menambah jejeran kekuatan massa rakyat yang dikenal berasal dari basis intelektual, moral, kedaerahan, agama dan unsur kepentingan partai politik.

Ruang publik (public sphere) pada dasarnya merupakan ruang yang tercipta dari kumpulan orang-orang tertentu dalam konteks sebagai kalangan borjuis yang diciptakan seolah-oleh sebagai bentuk penyikapan terhadap otoritas publik. Hal ini muncul karena adanya perubahan kultur warga dalam menanggapi regulasi maupun realitas politik dan dengan semakin intelektualnya warga, melek media, akses terhadap karya-karya yang bermutu, buku sastra yang mudah didapatkan, dan juga konsumsi yang lebih krirismelalui berita yang dipublikasikan. Menurut Habermas (2010) mengatakan ruang publik merupakan arena argumentasi terjadi dan tidak dapat diklaim sebagai teritori oleh organisasi apapun kaena ruang publik sebuah daerah otonom yang berbeda dari Negara atau pasar. Ruang publik merupakan salah satu dari elemen kota yang memiliki peran penting. Dia berperan sebagai pusat interaksi dan komunikasi masyarakat baik formal maupun informal, individu atau kelompok. Pengertian ruang publik secara singkat merupakan suatu ruang yang berfungsi untuk kegiatankegiatan masyarakat yang berkaitan dengan sosial, ekonomi, dan budaya (Soeprapto, 2002).

Di Kota Medan setidaknya ada 4 (empat) OKP yang dianggap memiliki kekuasaan luas dalam ruang publik yaitu Pemuda Pancasila (PP), Ikatan Pemuda Karya (IPK), Angkatan Muda Pembaharuan Indonesia (AMPI) dan Forum Komunikasi Putra Putri Purnawirawan Indonesia (FKPPI). seiring perkembangan zaman dan waktu, ditambah dengan perkembangan sosial politk memberikan celah terhadap OKP untuk memanfaatkan organisasi sebagai wadah dalam mendapatkan keuntungan, karena sudah tidak menjadi rahasia publik bahwa pimpinan dan anggota OKP berlatar belakang dari seorang preman, pengusaha, politikus (kader partai politik) dan dekat aparat penegak hukum sehingga mereka kelihatan kebal hukum.

Sekarang ini, OKP dianggap sebagai gangster atau tempat kumpulan preman, sehingga orang yang tergabung di dalam suatu OKP akan memiliki rasa bangga dan keberanian dalam melakukan segala hal, merasa hebat dan berkuasa pada lahan yang telah dikuasai OKP nya. Pola okupasi ruang publik ini dilakukan dengan cara OKP mengklaim ruang publik tersebut. Membuat plank atribut keorganisasian dan 
kantor sekretariat di pinggir-pinggir jalan. Hingga mewarnai fasilitas publik dengan simbol-simbol organisasian.

\section{METODE PENELITIAN}

Metode penelitian yang digunakan oleh peneliti dalam penelitian ini adalah pendekatan kualitatif dengan metode etnografi dari Spradlay untuk memahami dan mengungkapkan tentang permasalahan yang diangkat dan hendak diteliti oleh peneliti. metode etnografi yang digunakan oleh peneliti adalah di kenal dengan nama, Developmental Research Sequence atau Alur Penelitian Maju Bertahap dan tujuan utamanya adalah memahami pandangan hidup dari sudut pandang penduduk asli(native's point of view), sehingga data yang dikumpulkan adalah data kualitatif (Spradley, 1997).

Teknik pengumpulan data dalam penelitian ini menggunakan wawancara dan observasi partisipasi dengan pengamatan sistematis dari aktivitas manusia dan pengaturan fisik dimana kegiatan tersebut berlangsung secara terus menerus dari fokus aktivitas bersifat alami untuk menghasilkan data lapangan.

\section{HASIL DAN PEMBAHASAN Pola Okupasi Ruang Publik}

Dalam menjalankan roda organisasi dan mensejahterakan anggota OKP, maka perlu dilakukan kerjasama dengan berbagai pihak agar OKP mendapatkan proyek yang diberikan oleh pemerintah ataupun swasta. OKP harus menempatkan diri sebagai konsultan atau patron client dari suatu proyek, proyek yang didapatkan harus dibagi dengan anggota yang lain, agar tidak memicu timbulnya kecemburan sosial diantara anggota OKP. Kerjasama yang dilakukan atas dasar rekomendasi dari relasi OKP tersebut, sehingga aliran dana yang diperoleh dapat mengalir dengan lancar menjadi salah satu sumber pendapatan OKP.

OKP bekerja sama dengan Dinas Perhubungan dalam mengelola parkiran yang berada di satu daerah, OKP akan memberikan sejumlah dana akomodasi kepada oknum Dishub agar diberikan kekuasaan dalam zonasi parkiran, disamping itu, pengelola bisnis baik hiburan atau pertokoan tidak lepas dari kerjasama yang dilakukan dengan OKP. Hal ini dilakukan agar tidak ada keributan yang ditimbulkan oleh OKP, karena apabila tidak diajak kerja sama oleh pengelola tersebut, maka akan ada keributan atau ketidaknyamanan yang ditimbulkan seperti pemecahan kaca pertokoan, pencurian pada malam hari dan tindak kriminalitas lainnya, sehingga mau tidak mau pengelola bisnis harus menjalin kerja sama dengan OKP, seperti data wawancara yang dikatakan Kurniawan (30 Tahun), salah satu Anggota OKP di Kota Medan :

"Bentuk kerjasama kami sebenarnya bang lebih kearah proposal yang diberikan kepada pengelola hiburan baik hotel, diskotik atau pertokoan, jadi kalau ada mau buat acara entah itu pelantikan, entah itu acara social, kami akan datangi hotel-hotel atau tempat hiburan itu bang, hasilnya memang tidak menentu bang, kadang Rp 500 ribu, kadang Rp. 1.5 juta, tergantung kedekatan dengan pengelola bang, atau dilihat dulu ramai tidak yang berkunjung ke tempat tersebut bang, kalau rame yang berkunjung, trus dikasih dia Rp. 500 ribu, biasaanya kami minta tambah bang, dan biasanya ditambah orang itu entah Rp 200 ribu lagi, karena orang itu kan takut juga kalau gak ditambah, malamnya kadang ada perusakan yang dibuat bang, terus kalau kerja sama dengan pemerintah biasanya banyak dilakukan OKP kayak PP sama IPK, biasanya PP punya relasi ke PD pasar dan IPK ke Dishub bang, kalau kami memang khusus untuk nanduk-nanduk hotel ataupun tempat hiburan bang dan biasaanya sama itu dengan AMPI bang, AMPI juga kalau tidak salah nanduknanduk tempat hiburan sama hotel bang. (Wawancara, 22 Agustus 2018)

Masyarakat dan pedangang yang melakukan kegiataan ekonomi jual beli tersebut diberikan kenyamanan agar terhindar dari aksi pencopetan atau 
perampokan, ditambah lagi rasa keamanan yang diberikan kepada pelanggan dengan adanya lahan parkiran yang dijaga oleh salah satu anggota OKP, walaupun dalam melaksanakan penjagaan parkir memakai seragam khas orangenya dan memakai kartu identitas, namun sebenarnya penjaga parkir yang berada di Pasar Tradisonal merupakan dari anggkota OKP.

Bukan hanya menghiasi ruang publik dengan aksi-aksi jalanan yang brutal, perusakan lapak atau bangunan tertentu, namun juga memanfaatkan arus demokratisasi dengan cara mendukung para tokohnya agar berhasil masuk di jabatan formal pemerintahan. Kehadiran OKP juga tak jarang menebar teror dan ancaman, namun disisi lain dibutuhkan dan diperebutkan oleh kalangan tertentu yang berkepentingan dalam hal ini elite politik.

Adanya kebijakan pemerintah dalam otonomi daerah, peran para Organisasi Kemasyarakatan Pemuda (OKP) seolah mengganti peran polisi atau TNI dalam pengaturan politik keamanan di tengah masyarakat, jaringan yang dimiliki bahkan melewati batas kuasa politik pemrintahan dan masyarakat. Dapat dikatakan bahwa pemerintah selalu membiarkan tumbuh kembangnya kekerasan yang dilakukan oleh OKP, walau terkadang pemerintah mencoba mengendalikan kekerasan tersebut, namun hasilnya tetap nihil. Hal ini dikarenakan OKP sudah ada dari dulu walaupun memiliki istilah berbeda yaitu preman. Preman tidak pernah hilang dari Kota Medan, bahkan mereka naik menjadi pemain politik yang mempesona dan menarik perhatian masyarakat luas.

\section{Proses Penguasaan Lahan}

Lahan yang dikuasai oleh OKP biasanya lahan tanah garapan. Tanah garapan merupakan tanah yang dimiliki oleh pemerintah yang disalahgunakan fungsinya. Pola penguasaan tanah garapan yang dilakukan oleh OKP dalam menguasai satu lahan tanah garapan adalah dengan menjual harga tanah lebih murah dibandingkan dengan kelompok tani, harga yang ditawarkan bisa lebih murah sampai $40 \%$ dari harga yang biasa diberikan. Secara otomatis masyarakat yang ingin membeli tanah garapan pasti merapat kepada para OKP, disamping itu OKP memberikan pengamanan terhadap tanaman yang ditanam di tanah tersebut agar tidak dirusak oleh kelompok tani. Untuk mendapatkan pembeli tanah garapan, tidak jarang para OKP menjanjikan bahwa tanah tersebut bisa saja dibebaskan dari kepemilikan pemerintah karena tidak akan dipakai lagi oleh pemerintah dan dapat menjadi hak milik melalui surat keputusan (SK) Camat.

Cara yang dilakukan agar para pembeli semakin percaya atas pembebasan tanah tersebut, maka dibangunlah tempat ibadah seperti mesjid dan gereja, kemudian dibangunlah sekolah-sekolah yang diawali dari sekolah PAUD hingga SD.

Pembangunan tempat ibadah dan sekolah inilah yang menandakan bahwa tanah itu bisa dibebaskan, setelah pembangunan tempat ibadah dan sekolah, maka diwajibkan bagi yang ingin membeli tanah garapan untuk membangun rumah semi permanen dan ditempati. Surat kepemilikan hanya berupa kwitansi dan penancapan plank nama di tanah yang dianggap telah dibeli. Hal ini senada dengan yang dikatakan bang Karim (43 Tahun) salah satu OKP di Kota Medan:

"tanah garapan ini kan tanah PTPN yang gak digunakan lagi, dari pada jadi lalang gak terurus, mending dimanfaatkan tanah itu, yang memanfaatkan pun kan pasti bisa membantu ekonomi dia, entah dia menanam jagung atau ubi. Jadi harganya pun pastilah lebih murah, namanya tanah tak bertuan, lagian harga itu sebenarnya bukan untuk jual beli tanah, tapi dana untuk menjaga tanah itu apabila sudah dijadikan kebun, nanti udah mau panen dipanen orang pula kalau tidak dijaga, makanya dana pembelian tanah itu untuk dana penjagaan sebenarnya. Tapi ada juga tanah itu yang akan dibebaskan oleh pemerintah, dari BPN kan pasti tau kita bocorannya tanah mana yang mau 
dibebaskan, kalau udah tau kita, otomatis harganya pun dinaikkanlah, dikasih syarat untuk yang beli supaya mendirikan rumah setidaknya semi permanen. Kalau sudah banyak pembeli yang mendirikan rumah, kita mintalah dana partisipasi untuk membangun sekolah atau mesjid, karena kalau sudah jadi perkampungan, kan pemerintah pun pasti berpikir dua kali melakukan penggusuran, apalagi tanah garapan itu udah lama ditempati, lagian masyarakat yang mengklaim tanah itu miliknya akan melakukan perlawanan kalau ada penggusuran, jadi tenaga tambahan lah sama kita, kita pun kalau udah banyak yang tinggal disitu, pasti ada tanah yang sudah kita ambil kian jadi milik kita, nanti tanah inilah yang jadi investasi besar kalau sudah dibebaskan pemerintah (Wawancara, 21 Agustus 2018)

Kelompok yang selalu menang dalam persaingan akan menjadi kelompok yang disegani, dipuji, dan ditakuti oleh kelompok lainnya. Perilaku organisasi adalah suatu studi yang menyangkut aspek tingkah laku manusia dalam suatu organisasi atau kelompok tertentu, meliputi aspek yang ditimbulkan dari pengaruh organisasi terhadap manusia.

Demikian juga terdapat aspek yang ditimbulkan dari pengaruh manusia terhadap organisasi yang tujuannya adalah untuk mengetahui perilaku manusia itu dapat mempengaruhi usaha pencapaian tujuan-tujuan tertentu (Amin, 2005).

Konflik juga dilakukan untuk memperebutkan lahan yang dianggap memiliki sumber ekonomi terbaik, karena untuk menjalankan keaktifan organisasi, dibutuhkan dan yang lumayan besar, sehingga tidak ada cara lain kecuali mengambil daerah yang sudah dikuasai oleh OKP lain.

Layaknya hukum rimba yang mengedepankan kekuatan, maka tidak diherankan lagi, konflik sudah makanan sehari-hari OKP dilapangan, ada konflik kecil yang hanya menghasilakan perkelahian, tetapi ada konflik besar yang bahkan mengakibatkan hilangnya nyawa dari anggota OKP.

\section{SIMPULAN}

Penguasaan lahan yang dilakukan oleh OKP di Kota Medan melalui konflik diantara OKP, lahan yang sama-sama diklaim sebagai daerah kekuasaannya harus dijaga agar tidak diklaim oleh OKP lainnya. Apabila satu daerah sudah diklaim sebagai daerah kekuasaan satu OKP, maka pengamanan di daerah tersebut dilakukan oleh OKP dan duit setoran dari keamanan diberikan kepada OKP. Disamping itu mereka melakukan kerjasama dengan pemerintah untuk mengganti peran pemerintah dalam bentuk tender proyek. Setelah itu mengelola parkiran ruang public seperti kios kuliner, pertokoan dan Pasar tradisional.

Kelompok OKP di Kota Medan melakukan penguasaan dengan pola penguasaan bekerja sama dengan pemerintah, apabila pemerintah tidak memberikan tender kepada salah satu OKP, maka OKP tersebut akan melakukan tindak kriminalitas secara terus menerus, sehingga pemerintah dengan sendirinya yang mengajak kerjasama dengan OKP. Kemudian proyek-proyek yang dilakukan baik pemerintah maupun swasta harus melalui OKP dalam penyaluran barang material, apabila tidak dilakukan, maka bangunan proyek tersebut akan diganggu dan dirusak. Disamping itu, proyek dari pemerintah dapat disalurkan kepada OKP yang mendukungnya, sehingga proyek lancer untuk menghidupi kesejahteraan OKP dan anggotanya.

\section{UCAPAN TERIMAKASIH}

Ucapan terima kepada istri dan anakanaku tercinta yang memberi semangat dan kasih sayangnya. Informan yang menyediakan waktunya diwawancarai baik masyarakat, Anggota OKP dan semua yang terlibat mengumpulkan data-data.

Karena itu ucapan Terima Kasih yang dalam kepada Bapak, Ibu dan kerabat sekalian, yang merupakan orang-orang 
Budi Saputra, Hidayat \& Ichwan Azhari, Pola Okupasi Ruang Publik Oleh OKP di Kota Medan Sumatera

yang sangat berperan dalam penyelesaian naskah penelitian ini.

\section{DAFTAR PUSTAKA}

Abdul, T. (1997). Pemuda Dan Perubahan Sosial. LP3ES. Jakarta

Aziz, M. (2013). Identitas Pemuda Tionghoa Pasca Reformasi: Nasionalisme dalam Transformasi Kepemimpinan pada Organisasi Sosial di Lasem, Jawa Tengah. Jurnal Studi Pemuda. UGM.

Bonde. F. (2018). Pemberdayaan Organisasi Kepemudaan Di Kecamatan Dumoga Barat Kabupaten Bolaang Mongondow. Jurnal Administrasi Publik. UNSRAT

Fitrah. E. (2016). Peningkatan Kapasitas Organisasi Kepemudaan Kabupaten Banyumas Dalam Menghadapi ASEAN Community 2015. Jurnal Insigna. UJS

Habermas, J. (2010). Transformasi struktural Ruang Publik. Yogyakarta: Kreasi Wacana

Hiryanto. (2015). Pengembangan model pelatihan kepemimpinan bagi organisasi kepemudaan di Daerah Istimewa Yogyakarta. Jurnal Penelitian Ilmu Pendidikan. UNY

Kisworo. B. (2014). Partisipasi Pemuda Dalam Program Karang Taruna Desa (Studi Pada Pemuda Di Dusun Kupang Kidul Desa Kupang Kecamatan Ambarawa). NFECE. UNNES

Mujiarjo. (2011). Okupasi Terhadap Ruang Publik Perkotaan. Jakarta. Universitas Indonesia

Amin, M. (2005). Politik Organisasi Pemuda Tingkat Lokal ( Kasus keterlibatan Pemuda Pancasil(PP), Ikatan Pemuda Karya (IPK) dan FKPPI dalam pemilihan Kepala Daerah Langsung 2005 di Kota Medan. PPs Ilmu Politik: Universitas Indonesia

Ningtyas. L. (2019). Efektivitas Dispora Dalam Pemberdayaan Generasi Muda (Studi Di Dinas Kepemudaan Dan Olahraga Kota Malang). JRP. UIM

Nirmalasari. T. (2018). Peran Tokoh Pemuda Dalam Meningkatkan Partisipasi Karang Taruna Di Desa Nanjung Margaasih. Jurnal Comm-Edu. IKIP Siliwangi.

Nurdiansyah, E. (2013). Peran Pemuda Dan Organisasi Kepemudaan Dalam Merevitalisasi Nilai-Nilai Pancasila Pada Kehidupan Masyarakat. Jurnal Pendidikan Ilmu Sosial. UPI

Susilawati. (2017). Peran Organisasi Kepemudaan Sebagai Komponen Pendukung Dalam Sistem Pertahanan Semesta (Studi Pada: Ikatan Pemuda Karya, Di Kota Medan). Jurnal Peperangan Asimetris. Universitas Pertahanan.

Soeprapto, R. (2002). Interaksionisme Simbolik, Perspektif Sosiologi Modern. Malang : Averroe.

Widiatmaka. P. (2016). Peran Organisasi Kepemudaan Dalam Membangun Karakter
Pemuda Dan Implikasinya Terhadap Ketahanan Pribadi Pemuda (Studi Pada Pimpinan Cabang Gerakan Pemuda Ansor di Kabupaten Sukoharjo Provinsi Jawa Tengah). JKN. UGM. 